\title{
Predictive Value of ERCC1 Expression on Treatment Response to Cisplatin- Based Regimens in Small Cell Lung Cancer: A Retrospective Analysis
}

\author{
Arpaci $\mathrm{RB}^{* 1}$, Kara $\mathrm{T}^{1}$, Yuksek $\mathrm{GE}^{2}$, Polat $\mathrm{Y}^{3}$, Arıcan $\mathrm{A}^{4}$, Arpaci $\mathrm{T}^{5}$ and Orekici $\mathrm{G}^{6}$ \\ ${ }^{1}$ Mersin University School of Medicine, Department of Pathology, Mersin, Turkey \\ ${ }^{2}$ Mardin State Hospital, Department of Pathology, Mardin, Turkey \\ ${ }^{3}$ Biruni University School of Medicine, Department of Pathology, Istanbul, Turkey \\ ${ }^{4}$ Mersin University School of Medicine, Department of Medical Oncology, Mersin, Turkey \\ ${ }^{5}$ Acibadem University School of Medicine, Department of Radiology, Adana, Turkey \\ ${ }^{6}$ Mersin University, Department of Biostatistics, Mersin, Turkey
}

${ }^{*}$ Corresponding author: Arpaci RB, Mersin University School of Medicine, Department of Pathology, 33110, Mersin, Turkey, Fax: +903243374305, Tel: +903243374300, E-mail: rabiabarpaci@gmail.com

Citation: Arpaci RB, Kara T, Yuksek GE, Polat Y, Arıcan A, et al. (2019) Predictive Value of ERCC1 Expression on Treatment Response to Cisplatin-Based Regimens in Small Cell Lung Cancer: A Retrospective Analysis. J Respir Dis Treat 1(1): 103. doi: 10.15744/2767-4649.1.103

Received Date: December 24, 2018 Accepted Date: April 14, 2020 Published Date: April 16, 2020

\begin{abstract}
We aimed to determine whether the excision repair cross-complementation group 1 (ERCC1) expression predicts response to cisplatinbased chemotherapy in patients with small cell lung cancer (SCLC). This was a retrospective study, in which hospital files of 31 patients ( 29 males, 2 females; mean age, $62.26 \pm 7.71$ years) were reviewed. All patients were treated with etoposide+cisplatin. The lung biopsy and mediastinal lymph node samples were applied anti-human monoclonal antibodies against ERCC1: immunohistochemical staining was considered positive if $25-100 \%$ of the cells showed nuclear staining, and negative if less than $25 \%$ of the cells showed negative or slight staining. Response to treatment was evaluated as regression (complete or partial response), progressive disease, or stable disease. Of the patients, 18 (58.1\%) had limited-stage, and 13 (41.9\%) had extensive-stage SCLC. Median follow-up duration was 15 months (range: 1-60 months). ERCC1 staining was positive in 9 of 31 patients (29.0\%). In 12 patients (38.7\%), tumor regression (complete or partial response) was obtained after chemotherapy. Tumor regression rate was higher in ERCC1 positive patients than those with negative ERCC1 expression ( $66.7 \%$ vs. $27.3 \%$, p=0.036). In conclusion, high expression of ERCC1 was associated with higher response rate to cisplatin-based regimens in patients with SCLC.
\end{abstract}

Keywords: Small Cell Lung Carcinoma; Cisplatin; Human ERCC1 Protein; Remission Induction; Immunohistochemistry

\section{Introduction}

Lung cancer is the most commonly diagnosed cancer and the leading cause of cancer death around the world [1,2]. It is divided into two broad categories: small cell lung cancer (SCLC) and non-small cell lung cancer (NSCLC). SCLC is derived from cells exhibiting neuroendocrine characteristics and accounts for 15-20\% of new lung cancer cases. SCLC is highly malignant and an aggressive type of lung cancer [3,4]. Despite improvements in treatment, five-year survival for patients with SCLC is only 5-10\% [5]. At the time of diagnosis, approximately $30 \%$ of patients with SCLC have limited-stage disease, which confined to the hemithorax of origin, the mediastinum or the supraclavicular lymph nodes; while $70 \%$ of patients have extensive-stage disease, which presents outside of the hemithorax [6]. While five-year survival up to $14 \%$ has been reported for patients with limited-stage disease, $<1 \%$ of patients with extensive-stage disease can survive beyond 12 months [7].

Cisplatin-based regimens form the basis of chemotherapy in the management of SCLC. Combination of chemotherapy and radiotherapy results in complete response rate of $50-80 \%$ in limited-stage disease. In case of extensive-stage disease, the main treatment is a combination of cisplatin with either etoposide or irinotecan, which provides response rate of $60-80 \%$ and median survival of 7-12 months $[8,9]$.

Cisplatin, a platinum agent, exerts its anti-tumor activity by binding to DNA and creating platinum-DNA adducts that can lead to cell destruction [10]. Nucleotide excision repair, which has a central role among DNA repair pathways, has been associated with resistance to cisplatin-based chemotherapy by recognizing and removing cisplatin-induced DNA adducts. The excision repair 
cross complementation group 1 (ERCC1) enzyme plays a rate-limiting role in the nucleotide excision repair pathway [11,12]. Current data suggest that ERCC1 is a potentially useful marker for predicting clinical resistance to cisplatin in NSCLC $[10,13]$. In NSCLC patients treated with platinum-based chemotherapy, response and survival rates have been reported to be lower in patients with high expression of ERCC1 than those with low expression of ERCC1 [10]. Prognostic value of ERCC1 has also been reported in cancers other than lung cancer, such as ovarian cancer, gastric adenocarcinoma, colorectal cancer, or esophageal cancer [14-17]. However, the role of ERCC1 in predicting response to cisplatin-based chemotherapy and prognosis of disease in patients with SCLC has not been studied extensively, and few previous studies on this subject have conflicting results [18-20]. In this retrospective pilot study, we aimed at evaluating the predictive value of ERCC1 expression for response to cisplatin-based chemotherapy in patients with SCLC and provide the basis for future studies on the clinical use of ERCC1 immunohistochemistry to predict resistance to chemotherapy.

\section{Materials and Methods}

\section{Study Design and Patients}

This was a retrospective study, which included 93 patients diagnosed with SCLC and followed up at our clinic between 2007 and 2011. Clinico-pathological and immunohistochemical data were complete in hospital files of 31 patients, thus data of these 31 patients were analyzed. Demographic, clinical, pathological, and immunohistochemical data were recorded. The study was approved by the Institutional Ethics Committee and performed in accordance with the latest version of Helsinki Declaration. The requirement for informed consent was waived due to the retrospective design of the study.

\section{Pathology and ERCC1 Immunohistochemistry}

Four-micrometer-thick sections were cut from the bronchoscopic lung biopsy and mediastinal lymph node samples that were fixed in $4 \%$ formaldehyde and embedded in paraffin, and stained with hematoxylin and eosin for pathological evaluation with light microscopy (Olympus Bx51, Olympus Corporation, Tokyo, Japan). Tissue sections were also applied anti-human monoclonal antibodies against ERCC1 (Excision Repair Cross Complementing antibody, mAb anti-ERCC1 antibody, 1/100 dilution, ERCC1 (8F1): sc-56673, U.S.) immunohistochemically. The positive controls for immunohistochemical ERCC1 expression were made by nuclear staining of tonsillar epithelium.

We used a standard protocol for the immunostaining of the samples. The specimens were exposed to $10 \mathrm{mM}$ citrate buffer (pH 6.0) and heated for 30 minutes in a water bath. Tumor samples were incubated for 60 minutes with a monoclonal antibody specific against the ERCC1 protein at a 1:100 dilution. Antibody binding was detected by means of an ABC kit and Mayers hematoxylin as the counterstain. Sections of normal tonsil tissues were included as external control.

Immunohistochemical staining was quantified using a grading system based on the percentage of tumor cells stained with ERCC1 according to Sereno et al. with slight modifications. It was considered positive if $25-100 \%$ of the cells showed nuclear staining, and negative if less than $25 \%$ of the cells showed negative or slight staining [18]. Four investigators evaluated ERCC1 staining under a light microscope at a magnification of 400x. They recorded the tumor cells that expressed ERCC1. The staining intensity was graded on a scale of 0 to 3 (with a higher number indicating a higher intensity and with epithelial cells in tonsil control tissue used as a reference). Five foci of representative areas were acquired at a magnification of $400 \mathrm{x}$ for each specimen. A total of 100 positive or negative tumor nuclei per specimen were counted with magnification of 400x on a Olympus BX51 microscope. The percentage of positive tumor nuclei was calculated for each specimen, and a proportion score was assigned as negative for staining less than $25 \%$ of tumor cells and positive for $25 \%-100 \%$. This proportion score was evaluated by the staining intensity of nuclei to obtain a final semiquantitative score.

\section{Management of Patients and Evaluation of Treatment Response}

The stage and the extent of the disease were determined on the basis of available staging procedures: physical examination, laboratory evaluation, pathology, and imaging tests (computed tomography, magnetic resonance imaging, X-ray, positron emission tomography, radionuclide bone scan, etc.) Two-stage system is used for staging of SCLC: limited-stage disease and extensivestage disease. Limited-stage is disease confined to the hemithorax of origin, the mediastinum or the supraclavicular lymph nodes. Extensive-stage is disease present beyond one hemithorax [21]. Treatment regimen was determined based on the stage and extent of the disease, patient's performance status, co-morbidities, clinical experience of our center, and consent of the patients. All of the patients included in the analysis were treated with etoposide+cisplatin chemotherapy regimen (etoposide $100 \mathrm{mg} / \mathrm{m} 2$, cisplatin 25 $\mathrm{mg} / \mathrm{m} 2$ ) on days $1-3$.

After treatment, patients were followed up with every 3 months, with radiological and clinical evaluation. Response to treatment was evaluated according to WHO response criteria and documented as regression (complete or partial response: $>30 \%$ decrease in the longest axis), progressive disease ( $>20 \%$ increase in the longest axis), or stable disease (neither partial response nor progressive disease) [22]. 


\section{Statistical Analysis}

Study data are presented using descriptive statistics (mean, median, range, standard deviation, freqeuncy and percentage). Distributions of study variables (age, gender, stage, ERCC1 expresion, response to therapy) were compared using students't test for continuous variables and the chi-square test or Fisher's exact test for categorical variables. Results were considered significant at $\mathrm{p}<0.05$.

\section{Results}

\section{Patient Characteristics}

Thirty-one patients (29 males, 2 females; mean age, 62.26 7.71 years) were included in the study. Median follow-up duration was 15 months (range: 1-60 months). Of the patients, 18 (58.1\%) had limited-stage, and 13 (41.9\%) had extensive-stage SCLC (Table 1). The age of the patients did not have a significant correlation with the stage of disease, ERCC1 expression, and response to therapy (Table 2). The sample images of pathology specimens from bronchoscopic lung biopsy and mediastinal lymph node samples are shown in Figure 1.

\begin{tabular}{|c|c|c|}
\hline Parameters & & Results \\
\hline Age (years) & & $62.26 \pm 7.71(47.00-79.00)$ \\
\hline \multirow{2}{*}{ Gender } & Male & $29(93.5 \%)$ \\
\cline { 2 - 3 } & Female & $2(6.5 \%)$ \\
\hline \multirow{2}{*}{ Stage } & Limited-stage & $18(58.1 \%)$ \\
\cline { 2 - 3 } & Extensive-stage & $13(41.9 \%)$ \\
\hline \multirow{2}{*}{ Response to therapy } & Regression & $12(38.7 \%)$ \\
\cline { 2 - 3 } & Stable disease & $6(19.4 \%)$ \\
\cline { 2 - 3 } & Progressive disease & $13(41.9 \%)$ \\
\hline \multirow{2}{*}{ ERCC1 } & Negative $(0-25 \%)$ & $22(71.0 \%)$ \\
\cline { 2 - 3 } & Positive $(25-100 \%)$ & $9(29.0 \%)$ \\
\hline
\end{tabular}

Regression corresponds to complete or partial response (>30\% decrease in the longest axis), stable disease is neither regression nor progressive disease, and progressive disease is $>20 \%$ increase in the longest axis. Age data are given as mean \pm standard deviation (min-max), other data are given as $\mathrm{n}(\%)$. Table 1: Demographic and clinical characteristics of 31 patients with small cell lung cancer

\begin{tabular}{|c|c|c|c|}
\hline & & Age (years) & \multirow{2}{*}{$\mathbf{p}$} \\
\hline & & (mean \pm standard deviation) & \\
\hline \multirow{2}{*}{ Stage } & Limited-stage $(\mathrm{n}=18)$ & $62.72 \pm 8.62$ & \multirow{2}{*}{0.7} \\
\hline & Extensive-stage $(n=13)$ & $61.62 \pm 6.52$ & \\
\hline \multirow{2}{*}{ ERCC1 } & Negative $(n=22)$ & $60.68 \pm 7.17$ & \multirow{2}{*}{0.075} \\
\hline & Positive $(n=9)$ & $66.11 \pm 8.04$ & \\
\hline \multirow[t]{3}{*}{ Response to therapy } & Regression $(n=12)$ & $61.92 \pm 8.67$ & \multirow{3}{*}{0.772} \\
\hline & Stable disease $(n=6)$ & $64.33 \pm 8.21$ & \\
\hline & Progressive disease $(n=13)$ & $61.62 \pm 6.99$ & \\
\hline
\end{tabular}

Table 2: The mean age of study patients $(n=31)$ with respect to stage of small cell lung cancer, ERCC1 expression, and response to therapy

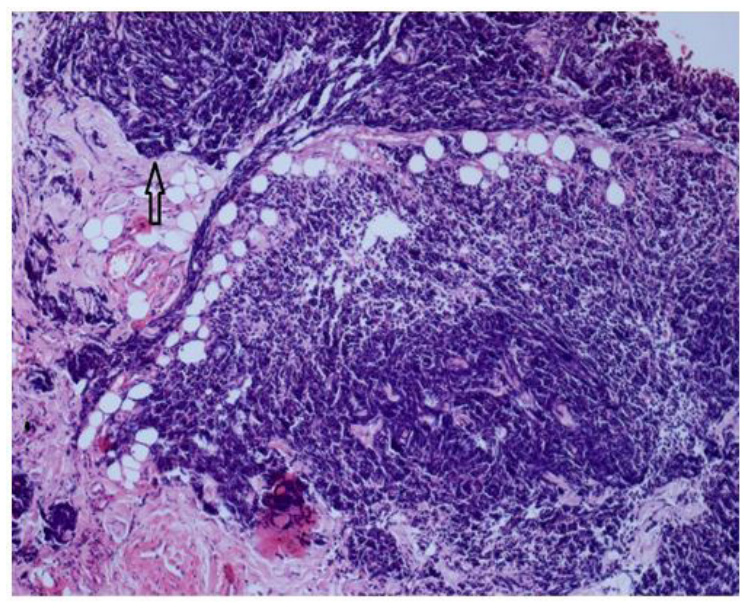

Figure 1a: Small cell lung cancer with atypical cells showing crush artefact in mediastinal lymph node biopsy specimen (a) 


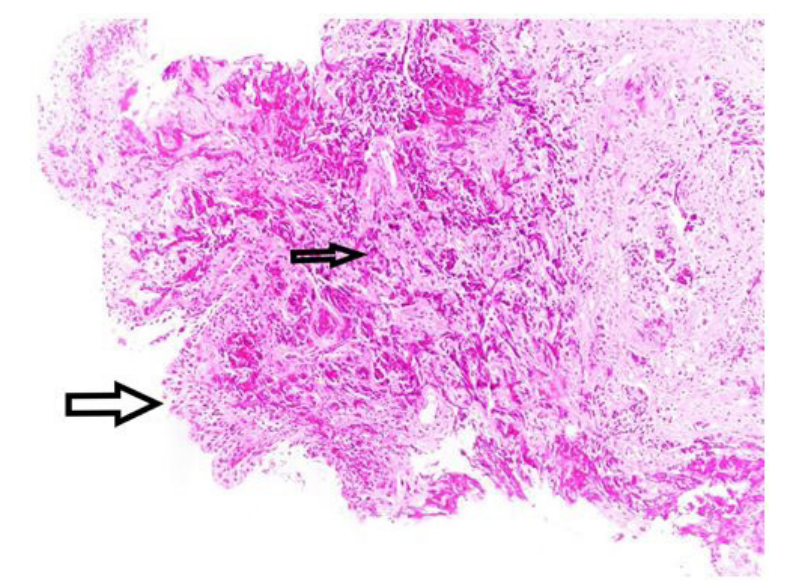

Figure 1b: In bronchial mucosa subepithelial infiltrates $(\mathbf{b})(\mathrm{H} \& \mathrm{E}, \times 100)$

\section{ERCC1 Expression}

ERCC1 immunohistochemical staining was positive in 9 of 31 patients (29.0\%). Samples of positive and negative immunohistochemical stainings are shown in Figure 2.

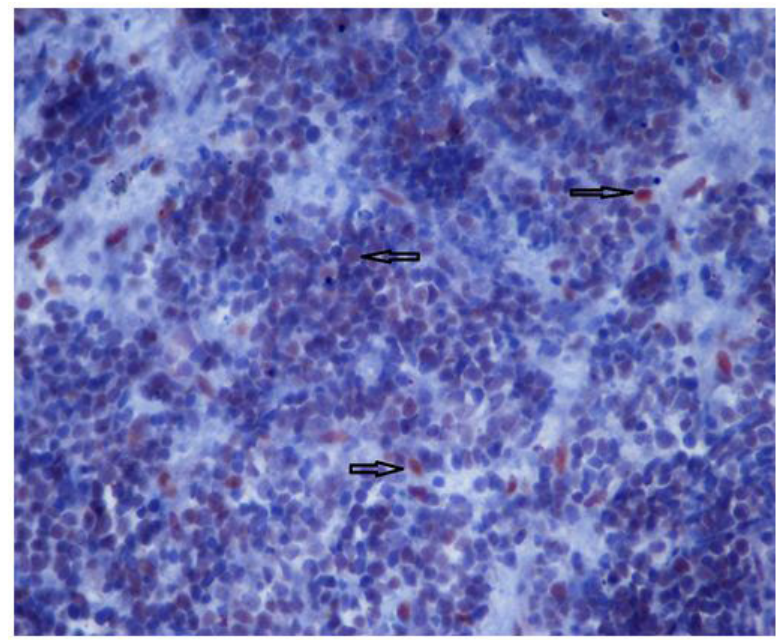

Figure 2: Positive ERCC1 immunohistochemical staining in $60 \%$ of atypical cells of infiltrating small cell lung cancer (ERCC1 positive) in mediastinal lymph node biopsy specimen (a)

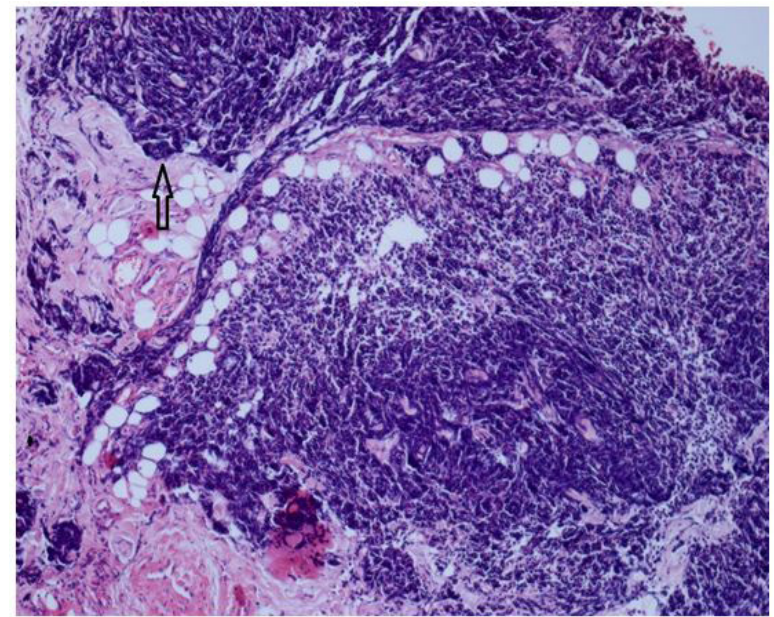

Figure 2b: Negative ERCC1 immunohistochemical staining (ERCC1 negative) in atypical small cell lung cancer cells showing subepithelial infiltration and crush artefact in bronchial mucosa biopsy specimen (b) (ERCC1, ×400)

\section{ERCC1 Expression and Response to Treatment}

In 12 patients (38.7\%), tumor regression (complete or partial response) was obtained after chemotherapy. Tumor regression rate was higher in ERCC1 positive patients than those with negative ERCC1 expression (66.7\% vs. $27.3 \%, \mathrm{p}=0.036)$ (Table 3, Figure 3). 


\begin{tabular}{|c|c|c|c|c|c|c|c|c|}
\hline & & \multicolumn{2}{|c|}{ Stage } & \multicolumn{3}{|c|}{ Response to therapy } & \multicolumn{2}{|c|}{ ERCC1 } \\
\hline & & $\begin{array}{l}\text { Limited-stage } \\
\qquad(\mathrm{n}=18)\end{array}$ & $\begin{array}{l}\text { Extensive-stage } \\
\quad(\mathrm{n}=13)\end{array}$ & $\begin{array}{l}\text { Regression } \\
(\mathrm{n}=12)\end{array}$ & $\begin{array}{l}\text { Stable disease } \\
\qquad(\mathrm{n}=6)\end{array}$ & $\begin{array}{l}\text { Progressive disease } \\
\qquad(\mathrm{n}=13)\end{array}$ & $\begin{array}{l}\text { Negative } \\
(\mathrm{n}=22)\end{array}$ & $\begin{array}{l}\text { Positive } \\
(\mathrm{n}=9)\end{array}$ \\
\hline \multirow{3}{*}{ Gender } & Male $(n=29)$ & $18(62.1 \%)$ & $11(37.9 \%)$ & $11(37.9 \%)$ & $6(20.7 \%)$ & $12(41.4 \%)$ & $20(69 \%)$ & $9(31 \%)$ \\
\hline & Female $(n=2)$ & $0(0 \%)$ & $2(100 \%)$ & $1(50 \%)$ & $0(0 \%)$ & $1(50 \%)$ & $2(100 \%)$ & $0(0 \%)$ \\
\hline & $\mathrm{p}$ & \multicolumn{2}{|c|}{0.055} & \multicolumn{3}{|c|}{0.639} & \multicolumn{2}{|c|}{0.232} \\
\hline \multirow{3}{*}{ Stage } & Limited-stage $(\mathrm{n}=18)$ & - & - & $6(33.3 \%)$ & $3(16.7 \%)$ & $9(50 \%)$ & $12(66.7 \%)$ & $6(33.3 \%)$ \\
\hline & Extensive-stage $(\mathrm{n}=13$ ) & - & - & $6(46.2 \%)$ & $3(23.1 \%)$ & $4(30.8 \%)$ & $10(76.9 \%)$ & $3(23.1 \%)$ \\
\hline & $\mathrm{p}$ & \multicolumn{2}{|c|}{-} & \multicolumn{3}{|c|}{0.559} & \multicolumn{2}{|c|}{0.532} \\
\hline \multirow{3}{*}{ ERCC1 } & Negative $(\mathrm{n}=22)$ & $12(54.5 \%)$ & $10(45.5 \%)$ & $6(27.3 \%)$ & $6(27.3 \%)$ & $10(45.5 \%)$ & - & - \\
\hline & Positive $(n=9)$ & $6(66.7 \%)$ & $3(33.3 \%)$ & $6(66.7 \%)$ & $0(0 \%)$ & $3(33.3 \%)$ & - & - \\
\hline & $\mathrm{p}$ & \multicolumn{2}{|c|}{0.532} & \multicolumn{3}{|c|}{0.036} & \multicolumn{2}{|c|}{ - } \\
\hline
\end{tabular}

Data are given as $\mathrm{n}(\%)$.

Table 3: The relations between the stage of SCLC, response to therapy, ERCC1 expression, and gender of the patients

\section{Response to therapy in ERCC1 negative and positive patients}

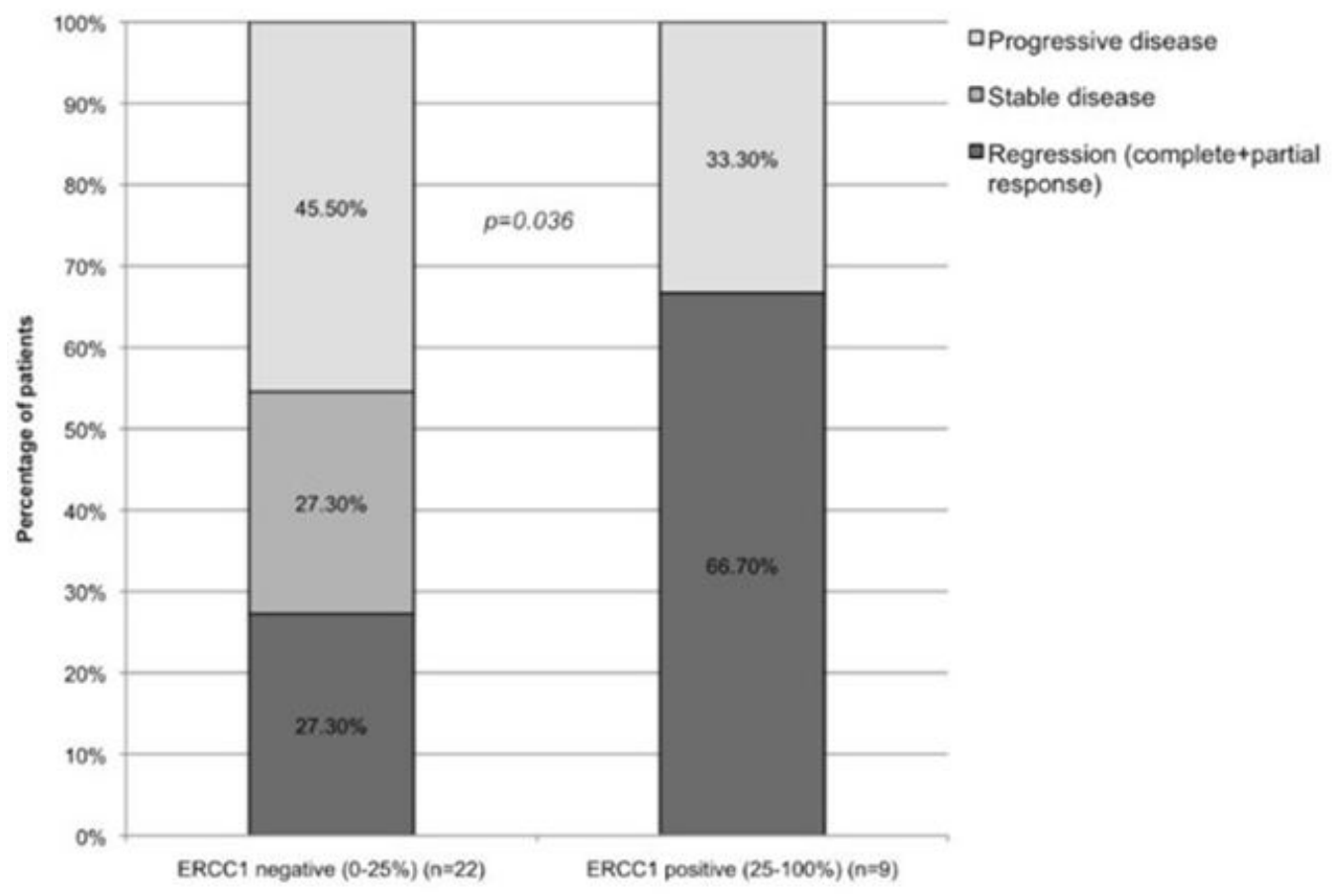

Figure 3: Response rates to chemotherapy in ERCC1 negative (0-25\%) and ERCC1 positive (25-100\%) patients

Gender and stage of SCLC had also no effect on response rates $(\mathrm{p}=0.639$ and $\mathrm{p}=0.559)$. There was no relation between ERCC1 expression and gender $(\mathrm{p}=0.232)$ or stage of the disease $(\mathrm{p}=0.532)$ (Table 3$)$.

\section{Discussion}

Although SCLC is an aggressive type of lung cancer, longer survival terms with good quality of life can be obtained with earlier and correct diagnosis, staging and appropriate multidisciplinary management of SCLC. On the other hand, resistance to chemotherapy is the main cause of poor outcome in patients with SCLC [23]. In order to manage the treatment, determining the risk group, prediction of treatment response to chemotherapy or prognosis of patients provides valuable information. On this ground, prognostic potential of polymorphisms in genes involved in DNA repair enzymes active in nucleotide excision repair, such as ERCC1, have been studied in some cancer types [4]. Although there are many clinical studies and meta-analyses showing the prognostic potential of ERCC1 protein expression and also being associated with increased resistance to platinum-based chemotherapy in NSCLC, SCLC data in literature are still inadequate to draw firm conclusions [24-29].

Sereno et al. found significant association between the positive immunohistochemistry expression of ERCC1 and the lack of platinum response $(\mathrm{p}=0.001)$ [18]. Additionally, significant association was found between better progression-free survival and negative 
ERCC1 immunostaining ( $\mathrm{p}=0.009)$ in 76 patients with SCLC. Lee et al. reported that high expression of ERCC1 was associated with poor overall survival, thus was an independent prognostic factor in patients with limited stage SCLC. Similarly Ceppi et al. showed that among 45 patients with limited disease, those with low ERCC1 expression had significantly longer survival (14.9 vs. 9.9 months, $\mathrm{p}=0.012$ ), while no significant role was found for ERCC1 in extensive disease patients [19,20]. In a recent analysis by Karachaliou et al., primary tumor samples of 184 SCLC patients treated with cisplation-etoposide were analyzed for ERCC1 mRNA expression [30]. The study found that in limited stage patients, high expression of ERCC1 was correlated with decreased median overall survival. However, Sodja et al. studied 77 SCLC patients and found no correlation between ERCC1 protein expression with either response rate to platinum-based chemotherapy or survival outcomes [31]. In the present study, out of 31 patients evaluated, 12 had tumor regression (complete or partial response) after standard cisplatin-etoposide chemotherapy, providing a response rate of $38.7 \%$, which is consistent with the literature [32]. ERCC1 immunohistochemical staining was positive in 9 of 31 patients (29.0\%). This rate was lower than the rate (52\%) in the study by Sereno et al., in which ERCC1 immunohistochemical staining was considered positive when more than $10 \%$ of the cells showed nuclear staining [18]. On the other hand, we considered positive staining if more than $25 \%$ of the cells showed nuclear staining. In contrary to the above-mentioned previous reports, the current study found that the treatment response rate was higher in ERCC1 positive patients than those with negative ERCC1 expression (66.7\% vs. $27.3 \%, \mathrm{p}=0.036)$.

It should be noted that the method of ERCC1 determination varies between studies in literature, thus it is difficult to meta-analyse or to draw a final conclusion from previous studies. Therefore, a consensus is required to provide consistent, validated ERCC1 assessment methodology.

The major limitations of our study were its retrospective design and small sample size. These limitations prevent us from reaching a definitive conclusion for the predictive value of ERCC1 expression on the cisplatin-based chemotherapy response on patients with SCLC. Furthermore, we did not evaluate prognostic criteria such as progression-free or overall survival; thus, we cannot speculate on the predictive value of ERCC1 expression on prognosis of SCLC. However, our preliminary finding on the conflicting relationship between ERCC1 expression and response to treatments will form a basis for further prospective clinical trials to obtain a definitive answer on the predictive value of ERCC1 in SCLC.

\section{Conclusion}

In conclusion, in contrast to previous reports, the findings of the present retrospective study showed that high expression of ERCC1 was associated with higher response rate to cisplatin-based regimens in patients with SCLC. In view of the previous studies and the present work, it is obvious that there is a relationship between the expression of ERCC1 and response to treatment with cisplatin-based chemotherapies in patients with SCLC, but to reach a definitive conclusion on the direction, extent, and clinical significance of this relationship, comprehensive and large-scale prospective clinical studies are needed.

\section{Acknowledgement}

We thank Dr. A.Arican for expert clinical assistance.

\section{References}

1. Parkin DM, Bray F, Ferlay J, Pisani P (2002) Global cancer statistics, 2002. CA Cancer J Clin 55: 74-108.

2. Jemal A, Bray F, Center MM, Ferlay J, Ward E, et al. (2011) Global cancer statistics. CA Cancer J Clin 61: 69-90.

3. Spira A, Ettinger DS (2004) Multidisciplinary management of lung cancer. N Engl J Med 350: 379-92.

4. Dela Cruz CS, Tanoue LT, Matthay RA (2011) Lung cancer: epidemiology, etiology, and prevention. Clin Chest Med 32: 605-44.

5. Gaspar LE, McNamara EJ, Gay EG, et al. (2012) Small-cell lung cancer: prognostic factors and changing treatment over 15 years. Clin Lung Cancer 13: 115-22.

6. Wallace E (2012) Small cell lung cancer: staging, treatment and prognosis. WIN 20: 43-44.

7. Jänne PA, Freidlin B, Saxman S, Johnson DH, Livingston RB, et al. (2002) Twenty-five years of clinical research for patients with limited-stage small cell lung carcinoma in North America. Cancer 95: 1528-38.

8. Sandler AB (2003) Chemotherapy for small cell lung cancer. Semin Oncol 30: 9-25.

9. Zatloukal P, Cardenal F, Szczesna A, Gorbunova V, Moiseyenko V, et al. (2010) A multicenter international randomized phase III study comparing cisplatin in combination with irinotecan or etoposide in previously untreated small-cell lung cancer patients with extensive disease. Ann Oncol 21: 1810-6.

10. Roth JA, Carlson JJ (2011) Prognostic role of ERCC1 in advanced non-small-cell lung cancer: a systematic review and meta-analysis. Clin Lung Cancer 12: 393-401.

11. Mu D, Hsu DS, Sancar A (1996) Reaction mechanism of human DNA repair excision nuclease. J Biol Chem 271: 8285-94.

12. Sancar A (1994) Mechanisms of DNA excision repair. Sci 266: 1954-56.

13. Mountzios G, Dimopoulos MA, Papadimitriou C (2008) Excision repair cross-complementation group 1 enzyme as a molecular determinant of responsiveness to platinum-based chemotherapy for non small-cell lung cancer. Biomark Insights 3: 219-26.

14. Li Q, Yu JJ, Mu C, Yunmbam MK, Slavsky D, et al. (2000) Association between the level of ERCC-1 expression and the repair of cisplatin-induced DNA damage in human ovarian cancer cells. Anticancer Res 20: 645-52.

15. Metzger R, Leichman CG, Danenberg KD, Danenberg PV, Lenz HJ, et al. (1998) ERCC1 mRNA levels complement thymidylate synthase mRNA levels in predicting response and survival for gastric cancer patients receiving combination cisplatin and fluorouracil chemotherapy. J Clin Oncol 16: 309-16. 
16. Shirota Y, Stoehlmacher J, Brabender J, Xiong YP, Uetake H, et al. (2001) ERCC1 and thymidylate synthase mRNA levels predict survival for colorectal cancer patients receiving combination oxaliplatin and fluorouracil chemotherapy. J Clin Oncol 19: 4298-304.

17. Joshi MB, Shirota Y, Danenberg KD, Conlon DH, Salonga DS, et al. (2005) High gene expression of TS1, GSTP1, and ERCC1 are risk factors for survival in patients treated with trimodality therapy for esophageal cancer. Clin Cancer Res 11: 2215-21.

18. Sereno M, Cejas P, Moreno V, Belda-Iniesta C, López R, et al. (2012) ERCC1 and topoisomerase I expression in small cell lung cancer: prognostic and predictive implications. Int J Oncol 40: 2104-10.

19. Lee HW, Han JH, Kim JH, Lee MH, Jeong SH, et al. (2008) Expression of excision repair cross-complementation group 1 protein predicts poor outcome in patients with small cell lung cancer. Lung Cancer 59: 95-104.

20. Ceppi P, Longo M, Volante M, Novello S, Cappia S, et al. (2008) Excision repair cross complementing-1 and topoisomerase II alpha gene expression in small-cell lung cancer patients treated with platinum and etoposide: a retrospective study. J Thorac Oncol 3: 583-9.

21. Kalemkerian GP (2012) Staging and imaging of small cell lung cancer. Cancer Imaging 11: 253-8.

22. Eisenhauer EA, Therasse P, Bogaerts J, Schwartz LH, Sargent D, et al. (2009) New response evaluation criteria in solid tumours: revised RECIST guideline (version 1.1). Eur J Canc 45: 228-47.

23. Chen YT, Feng B, Chen LB (2012) Update of research on drug resistance in small cell lung cancer chemotherapy. Asian Pac J Cancer Prev 13: 3577-81.

24. Hubner RA, Riley RD, Billingham LJ, Popat S, et al. (2011) Excision repair cross-complementation group 1 (ERCC1) status and lung cancer outcomes: a metaanalysis of published studies and recommendations. PLoS One 6: e25164.

25. Yan D, Wei P, An G, Chen W (2013) Prognostic potential of ERCC1 protein expression and clinicopathologic factors in stage III/N2 non-small cell lung cancer. J Cardiothorac Surg 8: 149.

26. Seyhan EC, Altın S, Cetinkaya E, Sökücü S, Abali H, et al. (2011) Prognostic significance of ERCC1 expression in resected non-small cell lung carcinoma. Ann Thorac Cardiovasc Surg 17: 110-7.

27. Bepler G, Olaussen KA, Vataire AL, Soria JC, Zheng Z, et al. (2011) ERCC1 and RRM1 in the international adjuvant lung trial by automated quantitative in situ analysis. Am J Pathol 78: 69-78.

28. Simon GR, Sharma S, Cantor A, Smith P, Bepler G, et al. (2005) ERCC1 expression is a predictor of survival in resected patients with non-small-cell lung cancer. Chest 127: 978-83.

29. Reynolds C, Obasaju C, Schell MJ, Li X, Zheng Z, et al. (2009) Randomized phase III trial of gemcitabine- based chemotherapy with in situ RRM1 and ERCC1 protein levels for response prediction in non-small-cell lung cancer. J Clin Oncol 27: 5808-15.

30. Karachaliou N, Papadaki C, Lagoudaki E, Maria Trypaki, Maria Sfakianaki, et al. (2013) Predictive value of BRCA1, ERCC1, ATP7B, PKM2, TOPOI, TOPOIIA, TOPOIIB and C-MYC genes in patients with small cell lung cancer (SCLC) who received first line therapy with cisplatin and etoposide. PLoS One 8: e74611.

31. Sodja E, Knez L, Kern I, Ovčariček T, Sadikov A, et al. (2012) Impact of ERCC1 expression on treatment outcome in small-cell lung cancer patients treated with platinum-based chemotherapy. Eur J Cancer 48: 3378-85.

32. Ganti AK, West WW, Zhen W (2013) Current concepts in the management of small cell lung cancer. Indian J Med Res 137: 1043-51.

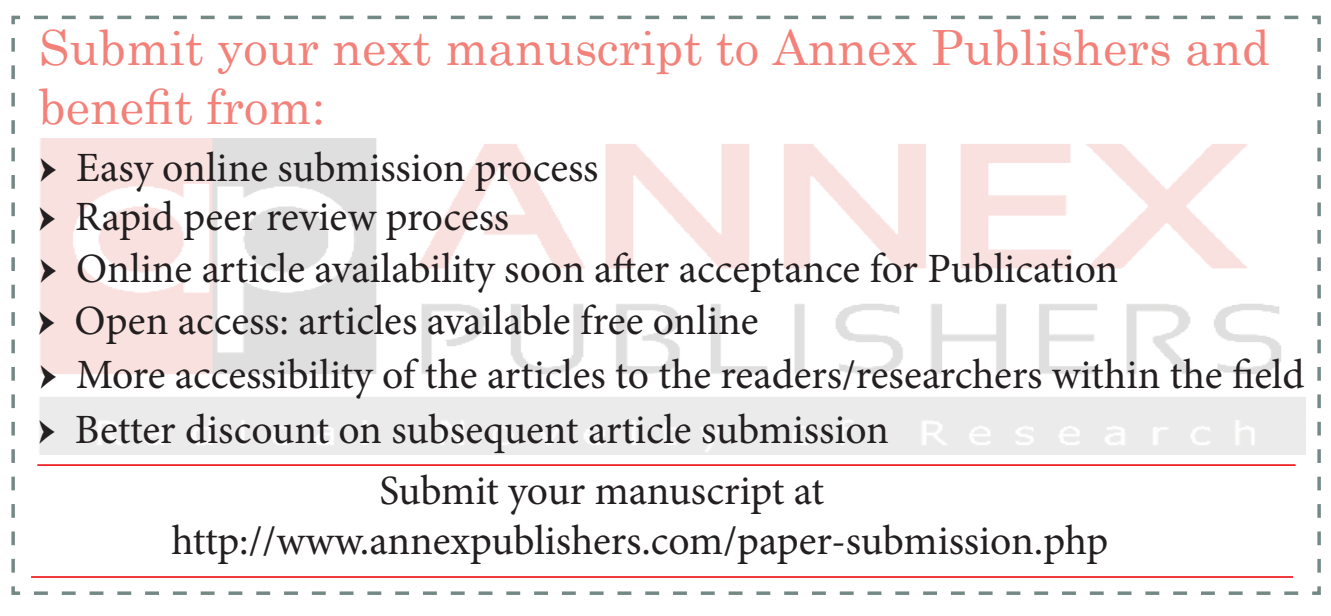

